\title{
Introducing Buton Natural Rock Asphalt New Materials for Bitumen Mofification and Soil Stabilization
}

\author{
Gatot Rusbintardjo $^{1 *}$, Nur Izzi M. Yusoff ${ }^{2}$, and Arafat Sulaiman Yerro $^{3}$ \\ ${ }^{1}$ Department of Civil Engineering, Faculty of Engineering, Sultan Agung Islamic University, Jalan Raya \\ Kaligawe km. 4 Semarang, 50112 Indonesia \\ ${ }^{2}$ Department of Civil and Structural Engineering, University Kebangsaan Malaysia - Malaysia \\ ${ }^{3}$ Department of Civil Engineering Abubakar TafawaBalewa University - Bauchi, Nigeria \\ * Corresponding author:gatotrsb@gmail.com
}

(Received: January 28 ${ }^{\text {th }}, 2018$; Revised: April $7^{\text {th }} 2018$; Accepted:August $23^{\text {rd }} 2018$ )

\begin{abstract}
The natural asphalt in the world which can be explored until today is Buton Natural Rock Asphalt (BNRA). The other natural asphalt like Trinidad Lake Asphalt Based on survey conducted by Directorate General of Mining Ministry of Energy and Mineral Resources Republik of Indonesia, amount of 650 million ton of BNRA are found in Buton island, yet until 92 years since BNRA in Buton Island discover by Hetzel, a Dutch Geolog, only 3.4 ton that have been explored to be used for road work. This paper reported the using of BNRA to modify bitumen to improve their properties in order to resist the high temperature rutting, and to stabilize clay soil, to improve their strenght. Bitumen penetration grade 80/100 which will be modified was blend by 15 to $65 \%$ of BNRA in increments of $5 \%$ by weight of bitumen, and to stabilized clay soil, amount of $2 \%$ to $8 \%$ in increements of $2 \%$ BNRA by weight of soil was added. To determine Penetration Index (PI) of neat bitumen and alsobitumen modified with BNRA, penetration at $25^{\circ}$ Celcius and softening point test were conducted. Penetration Index is the parameter to measure the temperature susceptibility of binder. The test results show that bitumen modified with 50\% BNRA have PI value -1.9 and bitumen modified with $60 \%$ BNRA have PI value -1.5, those value was higher compare to -3.2 the PI value of neat bitumen. The higher PI value of a binder, the lower its temperature susceptibility. All bitumen modified with BNRA then were used as binder of Hot Mix Asphalt (HMA) mixtures. All HMA mixtures using bitumen modified with BNRA as binder have Marshall Stability higher then HMA using neat bitumen as binder. Marshall test result shows that Marshall Stability of HMA with binder neat bitumen was 1294 $\mathrm{kg}$, while HMA with bitumen modified BNRA as binder have higher then $1294 \mathrm{~kg}$, especially for BNRA content $15 \%$ was $2229 \mathrm{~kg}$, and for BNRA content $50 \%$ was $2374 \mathrm{~kg}$. For clay soil stabilization, some tests such as Atteberg Limit, California Bearing Ratio (CBR), and Direct Shear were conducted on BNRA stabilized clay soil. The test results show that BNRA can improve the strenght of expansive clay.
\end{abstract}

Keywords:Buton Natural Rock Asphalt; Bitumen Modifier; Soil Stabilizer; Improve; Bitumen Properties; Soil Strength.

\section{Introduction}

Low cost of pavement construction is necessary to be continually efforted. Using Buton Natural Rock Asphalt (BNRA), the relative cheap price of natural asphalt, as pavement materials is one effort to get the low cost of pavement construction. Geological survey which was conducted by Directorate General of Mining Ministry of Energy and Mineral Resources Republik of Indonesiain Buton Island, the small island in South-East of Sulawesi Main Island, found amount of 650 million tons BNRA. Hetzel, a Dutch Geologist, is the first man found BNRA in the year 1926. Until now, 
94 years after BNRA was found, only about 3.4 million tons or nothing compare to 650 million tons of BNRA have been explored and used for road works by Indonesia Government, and use only for simple pavement maintenance like crack in surface pavement. Totally the amount of 650 tons have not maximally used for pavement construction. In this paper the efforts to use BNRA for pavement materials, therefore also an effort to maximally take advantage of BNRA for pavement construction, are reported. BNRA are used as bitumen modifier and soil stabilizer.

To be used as bitumen modifier, BNRA was crushed become $0.15 \mathrm{~mm}$ uniform particle size. Then to the bitumen penetration grade $80 / 100$, amount of $15 ; 20 ; 25 ; 30 ; 35 ; 50$ and $65 \%$ of those fine BNRA by weight of bitumen, were added. Laboratory tests such as Penetration at $25^{\circ}$ Celcius and Softening Point were performed to the mixture of bitumen-BNRA, and to the neat bitumen. From the result of Penetration and Softening Point test, Penetration Index (PI) can be determined. PI is the parameter to measure the temperature susceptibility of binder.

To stabilized expansive clay soil, 2, 4, 6, and $8 \%$ of BNRA by weight of soil was added. Atterberg limit, CBR, Direct Shear tests were performed in order to asses the strenght and properties of soil after being added with BNRA. To know how far BNRA improve the properties of expansive clay soil, sand also have used as stabilizer to get comparison between BNRA and sand.

Use for expansive clay stabilization, 2 to $8 \%$ of BNRA in increments of $2 \%$ was added to the clay soil. Atterberg Limit, California Bearing Ratio, Direct Shear tests were performed. To know how far BNRA can improve the properties of expansive clay soil, comparison was made by also stabilizing expansive caly soil with sand.

\section{Materials}

\subsection{BNRA}

As have been mentioned above, BNRA is the natural asphalt contain in the rocks in Buton Island, a small island located in South-East of Sulawesi Main Island. Deposit of rock asphalt can be discovered only 1 to 1.5 meters depth form the surface as shown in Fig. 1. Bitumen or asphalt content in the rock is range between 20 to $30 \%$. BNRA is a small particles with maximum size passing sieve number 30 or $0.60 \mathrm{~mm}$. Gradation and other propeties of BNRA were given in Table 1.

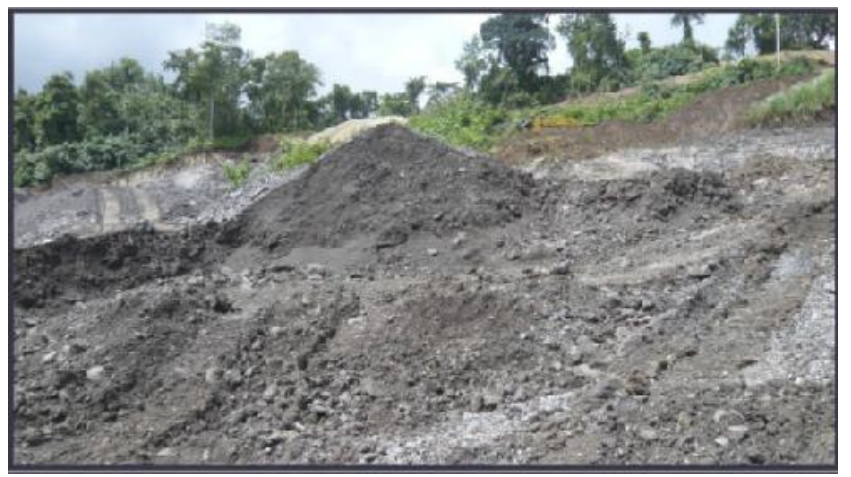

Fig. 1. BNRA in the surface of land in Buton Island (source: [1]) 
Table 1: Gradation and Properties of BNRA (source: [1])

\begin{tabular}{|c|l|c|}
\hline No. & \multicolumn{1}{|c|}{ Description } & Specification \\
\hline 1 & Gradation & \\
& Sieve no. 16 & $100 \%$ \\
& Sieve no. 30 & $54.02 \%$ \\
& Sieve no. 50 & $16.97 \%$ \\
& Sieve no. 100 & $1,75 \%$ \\
& Sieve no. 200 & $1.82 \%$ \\
\hline 2 & Bitumen content & $22.52 \%(20-30 \%)$ \\
\hline 3 & Solubility in $\mathrm{C}_{2} \mathrm{HCL}_{3}$ & $19.72(\min 18)$ \\
\hline 4 & Specific Gravity & 1.976 \\
\hline 5 & Flash Point & $232^{0}\left(\min 230^{0} \mathrm{C}\right)$ \\
\hline 6 & Water content & $0,81 \%(\max 1 \%)$ \\
\hline 7 & Volatile content by destilation & - \\
\hline
\end{tabular}

\subsection{Expansive clay soil}

Expansive clay soil which will be stabilized with BNRA was taken from kilometer 22 of the road between Semarang to Purwodadi. Table 2 display the Atterberg Limit of natural expansive clay soil found from the Soil Mechanic Laboratory Faculty of Engineering Sultan Agung Islamic University.

Table 2. Atterberg Limit of natural expansive clay soil

\begin{tabular}{c|c}
\hline Atterberg Limit test & Result \\
\hline Liquid Limit (LL) & $75.90 \%$ \\
\hline Plastic Limit (PL) & $42.00 \%$ \\
\hline Plasticity Index (PI) & $(75.90-42.00) \%$ \\
= LL - PL & $=33.90 \%$ \\
\hline
\end{tabular}

\section{Laboratory experiments}

\subsection{Modified Bitumen with BNRA}

To be able easily mix with bitumen, rough particles of BNRA was crushed into become and sieve to get $0.15 \mathrm{~mm}$ uniform particle size. The rough particles before crushing and fine particles after crushing are shown in Fig. 2.

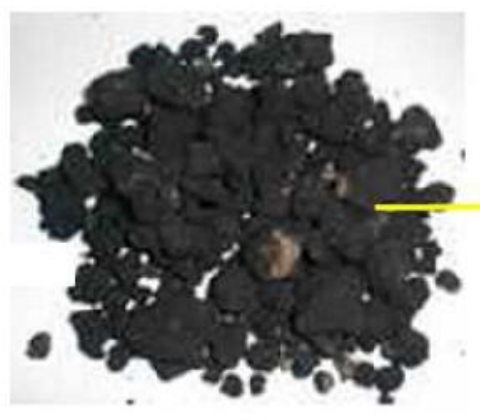

(a)

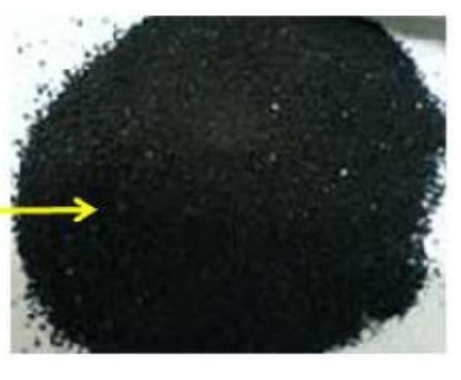

(b)

Fig. 2. (a) Particles of BNRA (b) Cruched BNRA diameter $0.15 \mathrm{~mm}$ 
15 to $35 \%$ in increments of $5 \%$ and $50 \%$ as well as $60 \%$ of fine BNRA then was added to the bitumen penetration rade 80/100. Mixing variable to be used in this research was mixing temperature $140^{\circ} \mathrm{C}$, mixing time 30 minutes, and stirring mixing speed was $500 \mathrm{rpm}$.

After mixing process completed, there are seven bitumen-BNRA mixtures resulted and to those seven bitumen-BNRA mixtures, Penetration Index (PI) was determined. PI is the parameter to measure the temperature susceptibility of binder.PI is determined from an bitumen's softening point (ring and ball test), its penetration at $25^{\circ} \mathrm{C}$, and an assumption that the penetration of bitumen at ist softening point is 800 [2], and value of PI was determined using nomograph.

Research activities then continue with using the mixture of bitumen-BNRA as binder of Hot Mix Asphalt (HMA) mixtures. The HMA mixtures used in this reasearch was asphaltic concrete wearing course and the gradationn of the mixtures was given in Table 3.

Table 3. Aggregate gradation for AC Wearing Course

\begin{tabular}{c|c|c|c}
\hline $\begin{array}{c}\text { Particle sieve size } \\
(\mathbf{m m})\end{array}$ & \% Passing sieve & $\begin{array}{c}\text { Particle sieve size } \\
(\mathbf{m m})\end{array}$ & \% Passing sieve \\
\hline 25.40 & 100 & 2.36 & $27-40$ \\
\hline 19.00 & 100 & 0.60 & $14-24$ \\
\hline 12.70 & $75-100$ & 0.30 & $9-18$ \\
\hline 9.50 & $60-85$ & 0.15 & $5-12$ \\
\hline 4.75 & $38-55$ & 0.075 & $2-8$ \\
\hline
\end{tabular}

To measure the strength of HMA mixtures, Marshall test was performed to HMA mixtures using to seven mixtures of bitumen-BNRA and neat bttumen as binder, and the test were conducted according to ASTM D 1559 -92 test procedure. [3]

\subsection{BNRA stabilized expansive clay soil}

To be able to thouroughly mix with soil, bitumen contain in the BNRA was activating. Activation bitumen in the BNRA was done by adding used bunker oil. BNRA which has been added with bunker oil were kept for 48 hours in shady place, and after 48 hours BNRA become soft indicate that bitumen in the BNRA have melted. Amount of 2, 4, 6, amd $8^{\wedge}$ of the melting BNRA were then added to the clay soil used as stabilizer. Atterberg limit, CBR, and Direct Shear test were performed to the mixtures of soil-BNRA and to the mixtures of soil-sand.

\section{Result and discussion}

\subsection{Modified bitumen}

All of the test results to bitumen-BNRA mixtures were analyzed by using student ' $t$ ' distribution and simple regresion model [4], and were explained as followed:

\subsubsection{Penetration test [5]}

Hypothetical of penetration test said that the value of bitumen penetration will decrease by increasing of BNRA content in the bitumen. Penetration test results for all bitumen-BNRA mixtures and neat bitumen ( $0 \%$ of BNRA content) were given in Table 4 . Statistical analysis by using student ' $\mathrm{t}$ ' distribution and simple regresion model were done to all of bitumen-BNRA mixtures and neat bitumen. show that penetration test results have confident coefficient $95 \%$, means that all penetration value of bitumen-BNRA mixtures is true and fit to the hypothesis. 


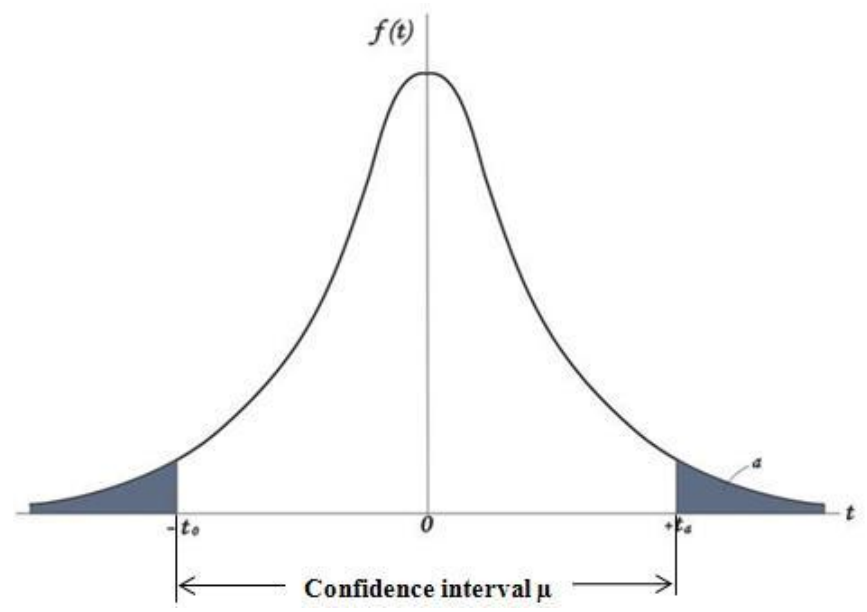

Fig. 3. Student ' $t$ ' distribution [4]

Regression model for all penetration test results are given in Fig. 4 and show that coefficient of correlation $\mathrm{R}=0.99$ and coefficient of determination $\mathrm{R}^{2}$ (R-square) $=0.98$, this mean that penetration tests results have very significant figure.

Table 4. The test result of Penetration, Softening Point, and Specific Gravity of bitumen-BNRA mixtures and neat bitumen. [5]

\begin{tabular}{c|c|c|c}
\hline $\begin{array}{c}\text { \% BNRA content } \\
\text { in the binder }\end{array}$ & $\begin{array}{c}\text { Penetration at } \mathbf{2 5}^{\mathbf{0}} \mathbf{C} \\
\mathbf{( d m m})\end{array}$ & $\begin{array}{c}\text { Softening Point } \\
\left.\text { temperature } \mathbf{(}^{\mathbf{0}} \mathbf{C}\right)\end{array}$ & Specific Gravity \\
\hline 0 & 83 & 39.5 & 1.02 \\
\hline 15 & 63 & 42.5 & 1.09 \\
\hline 20 & 52 & 42.5 & 1.019 \\
\hline 25 & 45.5 & 44 & 1.053 \\
\hline 30 & 45.5 & 45.5 & 1.09 \\
\hline 35 & 43 & 46 & 1.215 \\
\hline 50 & 28.5 & 52 & 1.44 \\
\hline 60 & 13 & 59.5 & 1.484 \\
\hline
\end{tabular}

\subsubsection{Softening Point test [5]}

Softening point or Ring and Ball test is the test conducted to the binder to measure the temperature when bitumen become soft. Opposite to the hypothesis of penetration test, the temperature of softening point will increase by increaing of BNRA content. This could be understatood since the lower of penetration value of bitumen mean the harder of bitumen, and the temperature to become soft will high. The results of softening test are given in coloumn 3 of Table 4, and from the statistical analysis using student ' $t$ ' distribution show that softening point test results have coefficient of confidence $95 \%$. The results of statical analysis by using of regression model (Fig. 5) give the coefficient of correlation $R$ was $99 \%$ and coefficient of determination $R^{2}$ (R-square) was also 99\%. This show that BNRA have strong influence to temperature softening point of bitumen-BNRA mixture, and very significant figure to the test resuls. 


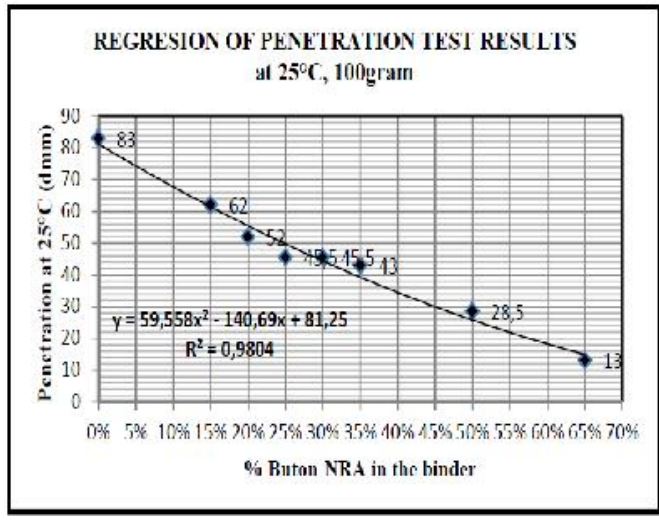

Fig. 4. Regression model for the results of Penetration test

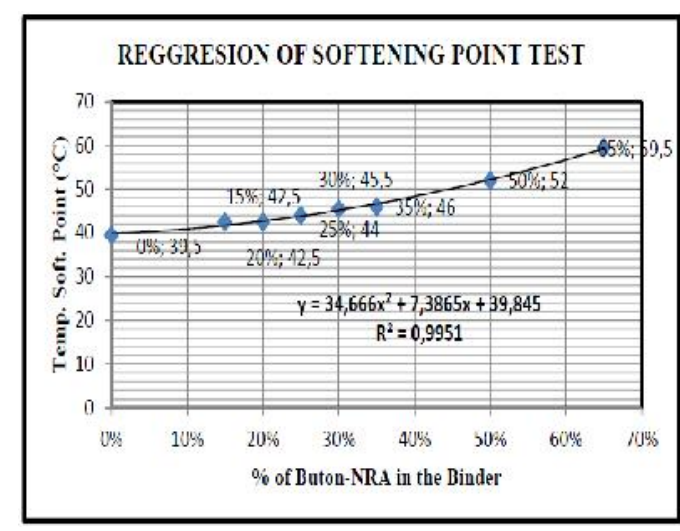

Fig. 5. Regression model for the results of Softening Point test

\subsubsection{Specific Gravity test [5]}

The results of specific gravity (SG) test given in coloumn 4 Table 4 . There is no special attention to be given to the results of specific gravity test. SG content for neat bitumen and bitumen-BNRA with BNRA content 15 to $30 \%$ almost similar in range 1.09. SG increase after BNRA content add to $35 \%$ become 1.215 and 1.44 for BNRA content $50 \%$, while for BNRA content $60 \%$, SG value was 1.484. Thos results could be understand since increasing of BNRA, the weight of bitumenBNRA will also increase. With the same volume, then the SG will higher.

\subsubsection{Penetration Index (PI) [5]}

Pfeiffer and van Doormaal [2] expresed the temperature susceptibility quantitatively by a term as 'Penetration Index" (PI).The PI is determined from an asphalt cement's (bitumen) softening point (ring and ball test), its penetration at $25^{\circ} \mathrm{C}$, and an assumption that the penetration of a bitumen at its softening point is 800 . This is refered to as PI (pen/s.p.). The lower the PI value of a bitumen, the higher its temperature susceptibility or inverse, the higher the PI alue of a bitumen, the lower its temperature susceptibility.

The results of PI value are given in Table 5, show that bitumen-BNRA have 50\% and 65\% BNRA content have highest PI value and mean less to temperature susceptibility. The simple regression model of the PI of all bitumen-BNRA mixtures give in Fig. 6. From those statistic analysis show that BNRA have very significant figure to the test results or have strongth influence to the improvement of bitumen caracteristic which is denoted by coefficient of correlation $\mathrm{R}$ was $96 \%$, and coefficient of determination $\mathrm{R}^{2}$ (R-square) was $93 \%$. Statistic analysis using Student ' $\mathrm{t}$ ' Distribution show that all PI data have coefficient of confidence $95 \%$.

\subsubsection{The results of Marshall test [5]}

The strength and stiffness of all of HMA mixtures using bitumen-BNRA as binder and HMA mixtures using neat bitumen as binder were tested by using Marshall Test, and the results show in Table 6.All HMA mixtures have stability and flow higher than specification and exhibits not influenced by BNRA content. The higher Marshall stability was reached by the 50\% BNRA content, namely $2374 \mathrm{~kg}$. The results were strongest by analysis of regression model which was given in Fig. 7. Regression model show that coefficient of determination R-square was only 0.5491 , and the coefficient of correlation R was only 0.7410 . 
Gatot Rusbintardjo, Nur Izzi M. Yusoff, Arafat Sulaiman Yerro

Tabel 5. Penetration Index value

\begin{tabular}{c|c}
\hline \% BNRA in the binder & Penetration Index (PI) \\
\hline 0 & -3.2 \\
\hline 15 & -2.8 \\
\hline 20 & -3.2 \\
\hline 25 & -3.0 \\
\hline 30 & -2.6 \\
\hline 35 & -2.6 \\
\hline 50 & -1.9 \\
\hline 60 & -1.5 \\
\hline
\end{tabular}

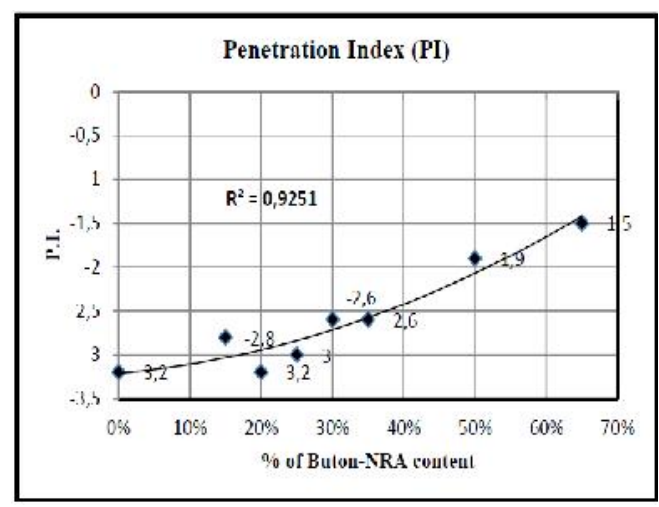

Fig. 6. Regression model for the results of Penetration Index (PI)

Table 6. Stability, Flow, and Stiffness of the bitumen-BNRA mixtures [5]

\begin{tabular}{c|c|c|c|c|c}
\hline \multirow{2}{*}{$\begin{array}{c}\text { \% of BNRA } \\
\text { Content }\end{array}$} & \multicolumn{2}{|c|}{$\begin{array}{c}\text { Stability } \\
\text { (kg) }\end{array}$} & \multicolumn{2}{c|}{$\begin{array}{c}\text { Flow } \\
(\mathbf{m m})\end{array}$} & $\begin{array}{c}\text { Stiffness } \\
\text { (kg/mm) }\end{array}$ \\
\cline { 2 - 6 } & Test & Specification & Test & Specification & \\
\hline 0 & 1294 & 750 & 7.7 & 2 to 4 & 169 \\
\hline 15 & 2229 & 750 & 8.3 & 2 to 4 & 268 \\
\hline 20 & 1974 & 750 & 8.4 & 2 to 4 & 236 \\
\hline 25 & 1788 & 750 & 7.7 & 2 to 4 & 233 \\
\hline 30 & 2052 & 750 & 8.4 & 2 to 4 & 243 \\
\hline 35 & 1955 & 750 & 7.1 & 2 to 4 & 274 \\
\hline 50 & 2374 & 750 & 7.6 & 2 to 4 & 311 \\
\hline 60 & 1661 & 750 & 7.9 & 2 to 4 & 169 \\
\hline
\end{tabular}




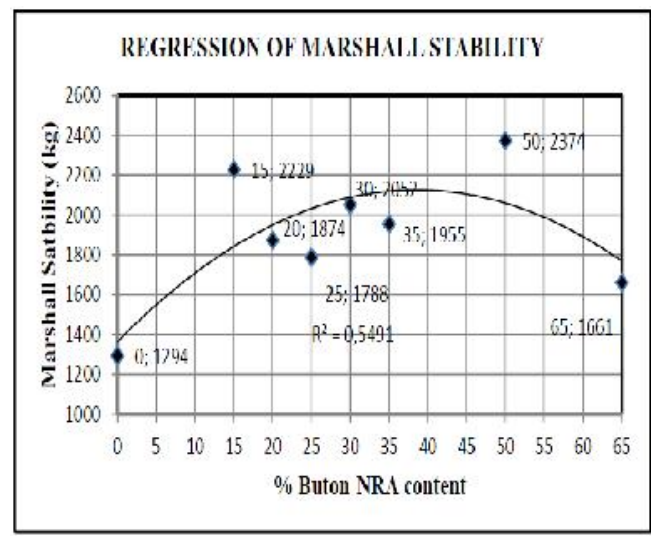

Fig.7. Regression model for the results of Marshall test

\subsection{BNRA Stabilized expansive clay soil 4.2.1. Atterberg Limit test}

Atterberg limits tests are the test performed on soil passing the \# 40 sieve. to find Plastic Limit (PL) and Liquid Limit (LL) of the soil. Plastic limit is the moisture content in the soil below which the soil is non-plastic. While Liquid limit is moisture content below which the soil behaves as a plastic material. At this moisture content, the soil is on the verge of becoming a viscous fluid. The different between LL and PL is called Plasticity Index (PI).

The results of Atterberg limit are given in Fig. 8 and show that the PI value soil-BNRA mixture decrease by increasing BNRA content in the soil. The results were corresponded to the hypotheses that the lower PI value, the less potential of soil to become expansive. In other word can be said that by adding more BNRA, the soil will become less expansive. Decreasing of PI value was caused by reducing of pores in the soil particles which filled with BNRA.

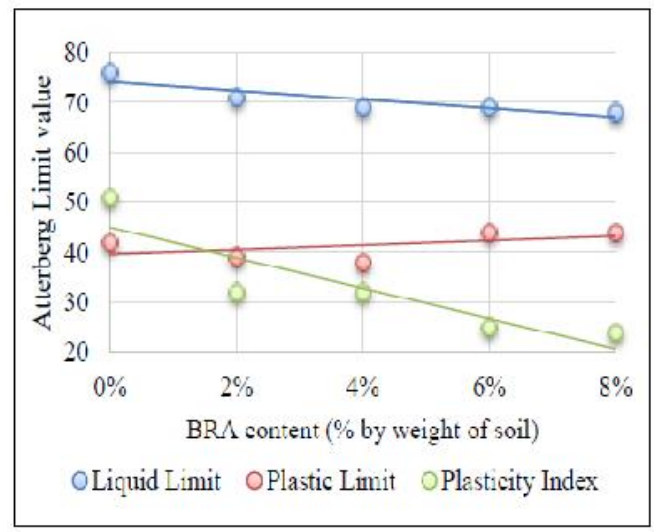

Fig.8. The results of Atterberg limit test

\subsubsection{Test the strength of the soil-BNRA mixtures}

The strength of soil after adding with BNRA was performed by using California Bearing Ratio or famous with CBR test. The CBR test results for soil-BNRA mixtures are given in Fig. 9., and show that the more BNRA content, the higher of CBR value. Statistical analysis by using regression model show BNRA has strength influence on improving the soil strength. This 
statement is indicated by coefficient of determination $\mathrm{R}^{2}$ (R-square) $=0.9230$ and coefficient of correlation $\mathrm{R}=0.9610$. It can be concluded that the hypotheses is true. From the statistical analysis was found that between soil and BNRA has linear value with equation: $y=51.45 x+2.126$. By using this equation, if the BNRA content in the soil is $20 \%$, then the CBR value is $12.43 \%$ and suitable for subgrade material of the pavement.

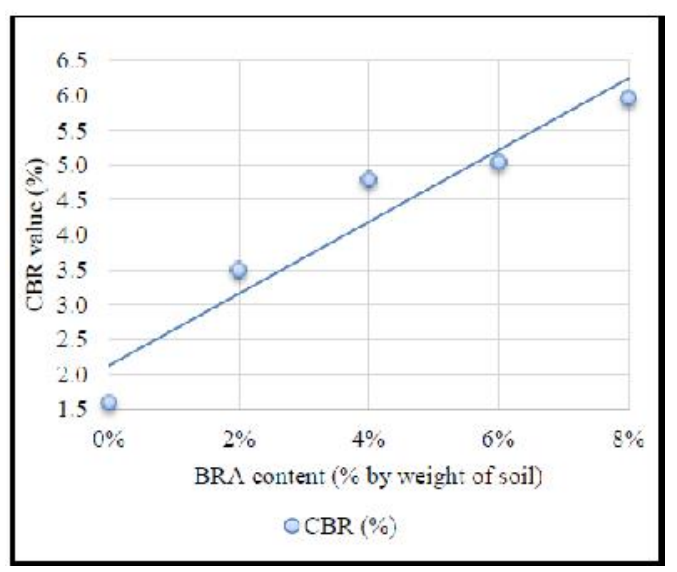

Fig.9. Statistical analysis using regression model for the results of CBR value

\subsubsection{Swelling Potential}

To correlate common soil tests with swelling potential, Holtzand Gibbs used Plasticity Index PI and Liquid Limit LL, while Chen used only LL [5]. Holtz and Gibbs as well as Chen divided swelling potential into four groups, low, medium, high, and very high. Tables 7 and 8 show the correlations with common soil tests to determine swelling potential which has been conducted byHoltzand Gibbs, and Chen respectively [5]. From both tables of correlation, and Atterberg limit test results of soil-BNRA and soil-Sand mixtures, it is shown that the swelling potential for soil after stabilizing with BNRA or sand is still very high.

Table 7.Correlations with common tests by Holtz and Gibbs [5]

\begin{tabular}{c|c|c|c}
\hline PI & $\begin{array}{c}\text { Shrinkage } \\
\text { Limit }\end{array}$ & LL & $\begin{array}{c}\text { Swelling } \\
\text { potential }\end{array}$ \\
\hline$<18$ & $<15$ & $<39$ & Low \\
$15-28$ & $10-16$ & $39-50$ & Medium \\
$25-41$ & $7-12$ & $50-63$ & High \\
$>35$ & $>11$ & $>63$ & Very High \\
\hline
\end{tabular}

Table 8.Correlations with common tests by Chen [9]

\begin{tabular}{c|c|c|c}
\hline $\mathbf{L L}$ & $\begin{array}{c}\text { Probable } \\
\text { Expansion }\end{array}$ & $\begin{array}{c}\text { Swelling } \\
\text { Pressure } \\
\mathbf{( k P a )}\end{array}$ & $\begin{array}{c}\text { Swelling } \\
\text { potential }\end{array}$ \\
\hline$<30$ & $<1$ & 50 & Low \\
$30-40$ & $1-5$ & $150-250$ & Medium \\
$40-60$ & $3-10$ & $250-1000$ & High \\
$>60$ & $>10$ & $>1000$ & Very High \\
\hline
\end{tabular}




\subsubsection{Direct shear test}

Fig. 10 shows the test results of direct shear test to soil-BNRA mixture to get cohesion values (c). The results show that 'c' of soil-stabilized with BNRA different with normal value of cohesion for soil, where the higher of cohesion values are the lower the value of Angle of Internal Friction $\varnothing$. Yet in this case, 'c' and $\varnothing$ both are high. This case can be explained as foloows: when to the soil was added BNRA and thoroughly blended, all particles of the soil will be bound by the melting bitumen from BNRA. This condition will make the mixtures of soil-BNRA become cohesive. But those cohesion is a false cohesion since in BNRA contains fine particles of rock, and the soilBNRA mixtures are clotted, hard and still in form of granular material. In view of this, the angle of internal friction $\varnothing$ increase with increasing the percentage of BNRA content.

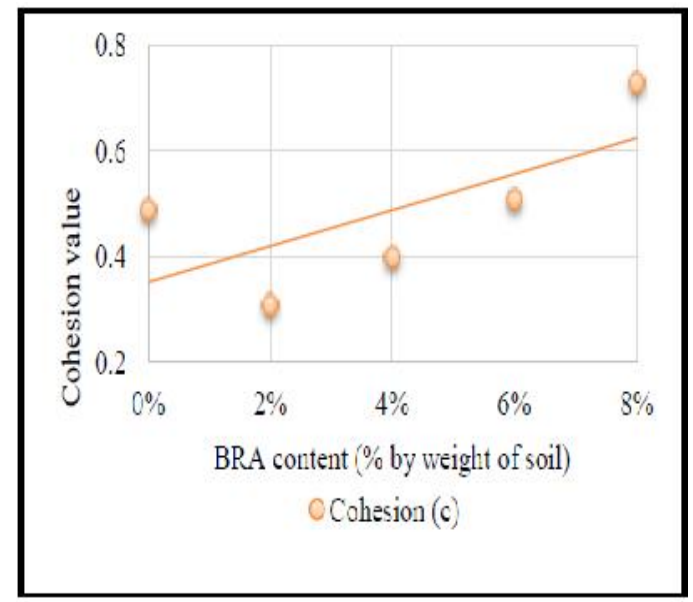

Fig. 10. The test resultstosoil-BNRA mixtures to getcohesion values

\subsection{Sand stabilizad soil}

Similar to the BNRA stabilized expansive clay soil, Atterberg limit, CBR, and direct shear tests were also performed to the sand stabilized soil. The results of Atterberg limit, CBR, cohesion value 'c', and angle of internal friction $\varnothing$, are given in Fig. 11, Fig. 12, Fig. 13, and Fig. 14 respectively. Each of the test results were discussed as follows.

\subsubsection{Atterberg Limit}

Beside in Fig. 11, the results of Atterberg limit test also are given in Table 9. The results correspond to the hypothesis that the lower of PI value is, the decrease possibility the potential of soil to become expansive. Decrease pf PI value was caused by the reduction of void in the soil that was filled by sand. That is why by adding more sand to the soil, the soil will become less expansive.

\subsubsection{California Bearing Ratio (CBR)}

Shown in Fig 12 of the results of CBR test to sand-stabilized expansive soil. From thet results show that the influence of sand to soil is very strongth, CBR value high if the percentage of sand content increase. This results were strenghtened by statistical analysis using simple regression model, where coefficient of determination $\mathrm{R}^{2}$ (R-square) is 0.9638 and coefficient of correlation $\mathrm{R}$ is 0.9823 , means that $\mathrm{CBR}$ value is very significant figure.

Table 9.Plasticity Index (PI) of sand stabilized soil

\begin{tabular}{c|c|c|c}
\hline \% of sand & LL & PL & PI \\
\hline 0 & 76 & 42 & 34 \\
\hline
\end{tabular}


Gatot Rusbintardjo, Nur Izzi M. Yusoff, Arafat Sulaiman Yerro

\begin{tabular}{c|c|c|c}
\hline 5 & 72 & 46.3 & 25.7 \\
\hline 10 & 71 & 35.3 & 37.9 \\
\hline 15 & 60 & 31.8 & 28.2 \\
\hline 20 & 59 & 29.2 & 29.8 \\
\hline 25 & 52 & 28.2 & 23.8 \\
\hline
\end{tabular}

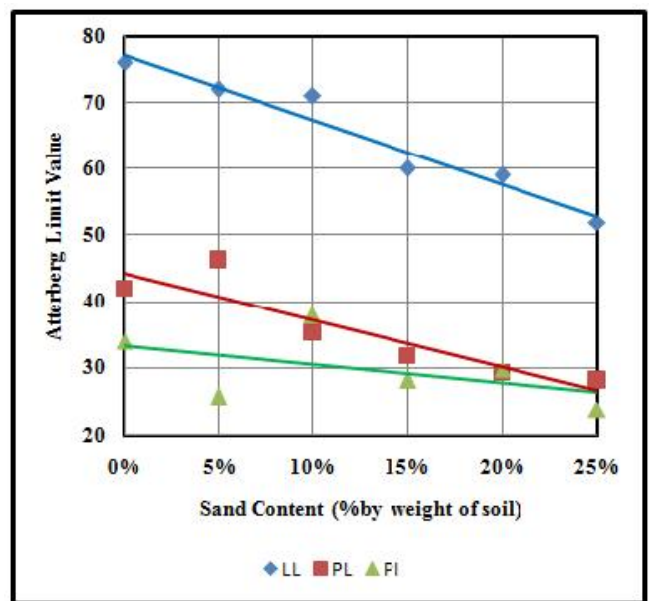

Fig. 11. The test results of Atterberg limit

\subsubsection{Direct Shear}

As shown in Fig. 13 and Fig. 14, angle of internal friction $\varnothing$ of sand-soil stabilization and cohesion value 'c' exhibit the normal value where the more sand added to the soil, the value of Øbecome higher, and the cohesion value 'c' low. Angle of internal friction $\varnothing$ of natural expansive clay was $14^{0}$ lower than after adding with sand, and cohesion value ' $c$ ' $0.49 \mathrm{~kg} / \mathrm{cm}^{2}$ higher than after adding with sand, therefore can be concluded that sand improved the properties of expansive clay soil.

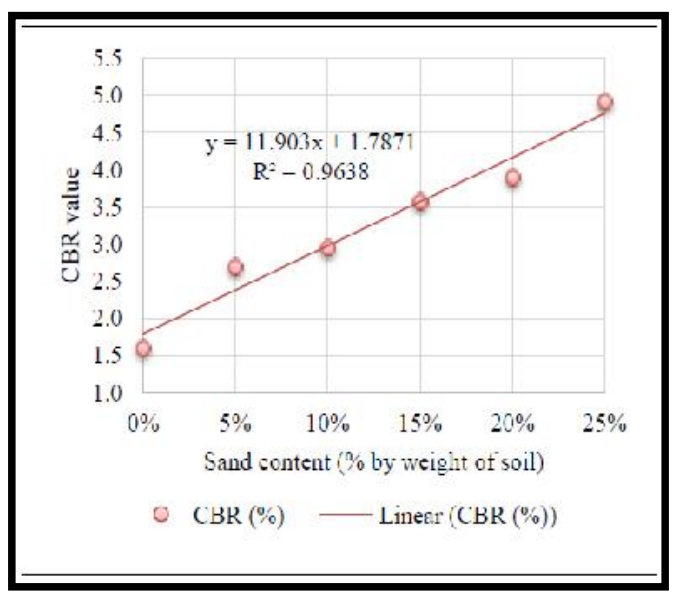

Fig. 12. The test results of CBR test 


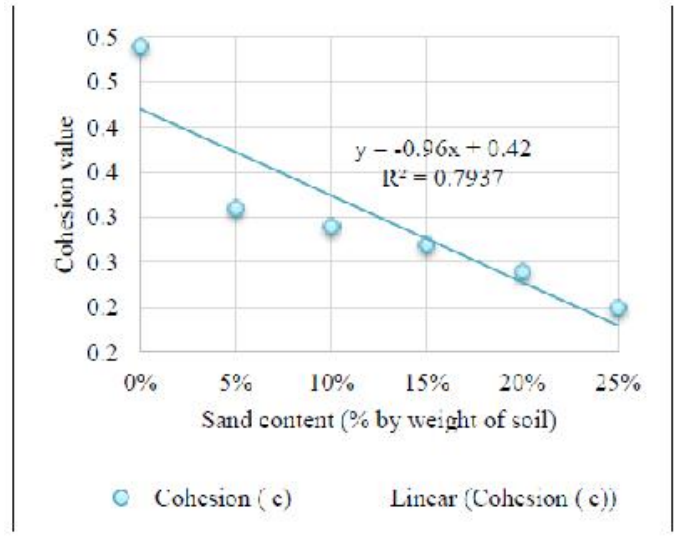

Fig. 13. Regression model for cohesion value of sand-soil stabilization

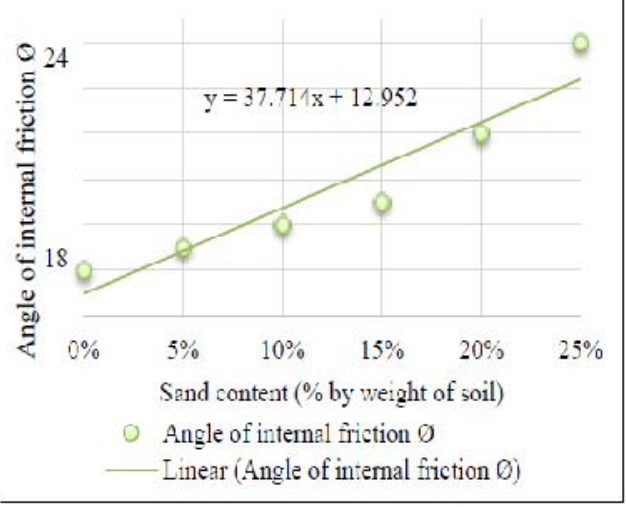

Fig. 14. Regression model for angle of internal friction $\varnothing$ of sand-soil stabilization

\subsubsection{Discussion on direct shear test results}

Cohesion value ' $c$ ' and angle of internal friction $\varnothing$ for soil-BNRA mixtures with $8 \%$ of BNRA content are 0.624 and $50.2^{0}$ respectively. While with the same percentage, the cohesion value ' $c$ ' and angle of internal friction $\varnothing$ are of soil-sand mixture is 0.34 as well as the value of angle internal friction $\varnothing$ of soil-sand mixtures is $16^{\circ}$. Those results are caused BNRA contains rock particles which makes soil-BNRA mixture to be clotted, hard, and granular which results in high vavlue of angel of internal friction.

\section{References}

[1] Buton Aphalt Indonesia Co. Ltd, 2006. A Private Company in Indonesia who trade BNRA

[2] J. Ph. Pfeiffer, ED., Properties of Asphalt Bitumen, Elsevier Publishing Company, Inc., New York, 1950.

[3] ASTM D1559 - 92: Standard Test Method for Resistamce to Plastic Flow of Bituminous Mixtures using Marshall Apparatus. Philadelphia U.S.: ASTM International 1992.

[4] Richard L. Scheaffer and James T. McClave (1990), Probability and Statistic for Engineers. Third Edition of PWS-KENT Publishing Company, Boston USA.

[5] Rusbintardjo, Gatot (2013), 'Utilization of Buton Natural Rock Asphalt as Additive of Bitumen Binder in Hot Mix Asphalt Mixtures' - International Journal of Advanced Materials Research - 2013.

[6] Donald P. Coduto 1994, Foundation Design - Principles and Practice. PRENTICE HALL Englewood Cliffs, N.J. 07632 pp 606. 